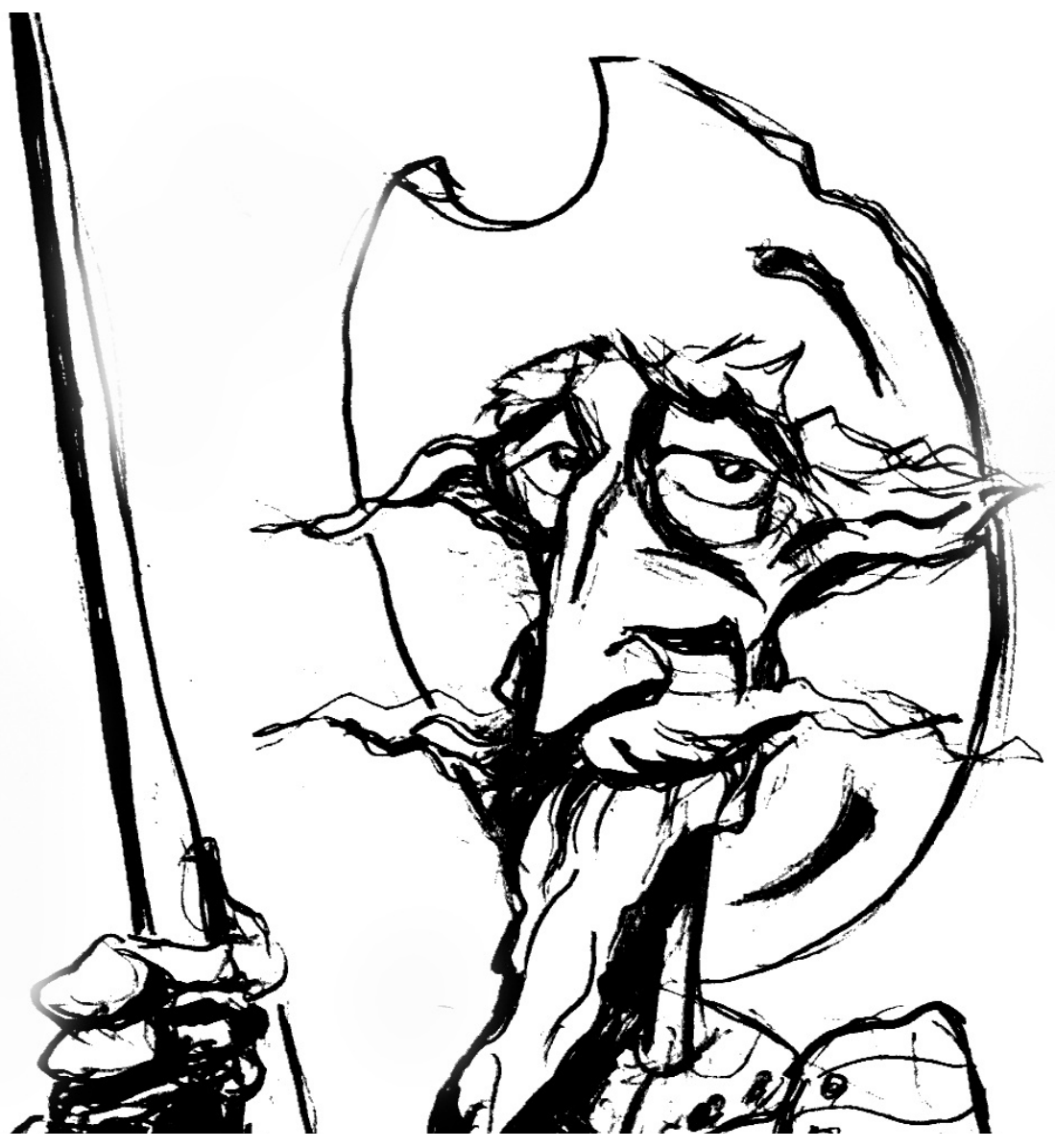

Trayectos y articulaciones socio-políticas en el teatro independiente santafesino, c. 1966-1984

[Luciano Alonso] 



\section{Trayectos y articulaciones socio-políticas en el teatro independiente santafesino, c. 1966-1984*}

\section{Trajectories and Socio-Political Articulations in the Independent Theater of Santa Fe, c. 1966-1984}

\section{LUCIANO ALONSO}

\section{Resumen}

Este artículo intenta presentar un desarrollo general del teatro independiente en la ciudad de Santa Fe, Argentina, hacia las décadas de 19601980. Se destaca la formación de una comunidad teatral en el seno de articulaciones sociopolíticas complejas, como ser vínculos de clases medias variadas y una relación ambivalente con las reparticiones estatales, incluso en los períodos dictatoriales. Ese marco temporal extendido permite relativizar y al mismo tiempo afirmar la excepcionalidad de la última dictadura militar, destacando los canales por los que pudieron expresarse subjetividades disidentes en el contexto de una gubernamentalidad autoritaria.

\section{Palabras clave}

Teatro; Articulaciones Socio-Políticas; Trayectorias; Gubernamentalidad Autoritaria

\begin{abstract}
This article attempts to present a general development of independent theater in the city of Santa Fe, Argentina, towards the 1960s and 1980s. The formation of a theater community in complex socio-political articulations, such as links of varied middle classes and an ambivalent relationship with state powers, even during dictatorial periods, is analyzed. This extended time frame allows us to review and at the same time affirm the exceptionality of the last military dictatorship, highlighting the channels through which dissident subjectivities could be expressed in the context of authoritarian governmentality.
\end{abstract}

\section{Keywords}

Theater; Socio-Political Articulations;

Trajectories; Authoritarian Governmentality

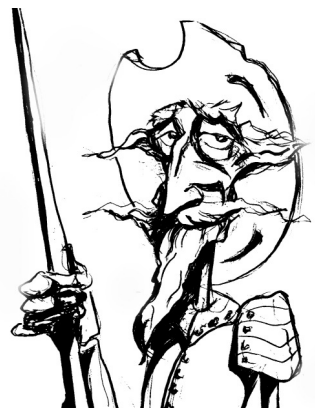

Recibido con pedido de publicación el 20 de diciembre de 2019

Aceptado para su publicación el 10 de marzo de 2020

Versión definitiva recibida el 3 de junio de 2020

Luciano Alonso, Universidad Nacional del Litoral (UNL), Santa Fe, Argentina; e-mail: lpjalonso8@gmail.com

* Agradezco los comentarios y aportes de las/los evaluadoras/es de la revista.

Esta obra se publica bajo licencia Creative Commons. Atribución-NoComercial-CompartirIgual 4.0 Internacional

Alonso, Luciano "Trayectos y articulaciones socio-políticas en el teatro independiente santafesino, c. 1966-1984", Prohistoria, Año XXIII, núm. 34, dic. 2020, pp. 219-247. 


\section{Introducción}

¿Cómo se construye una comunidad de artistas en una localidad de provincias y de qué manera es posible que expresen concepciones divergentes de las imperantes en medios socialmente conservadores? La alternancia entre gobiernos constitucionales y dictatoriales en la historia argentina del siglo $\mathrm{XX}$ marca sin dudas diferencias contextuales de envergadura, máxime en orden al proceso de brutal disciplinamiento social y exterminio de opositores que caracterizó a la experiencia del último gobierno de facto. Respecto de la ciudad de Santa $\mathrm{Fe}^{1}{ }^{1}$ es posible postular que los agentes individuales y colectivos del ámbito teatral se movieron en un constante juego de restricciones $y$ habilitaciones, no ya solo respecto del poder dictatorial sino más generalmente de aquello que se puede definir como una gubernamentalidad autoritaria en el plano local-regional. ${ }^{2}$ Incluso en los momentos más álgidos del terror de Estado, entre fines del gobierno constitucional de María Estela Martínez de Perón y la primera etapa del autodenominado "Proceso de Reorganización Nacional" (c. 1975-1978) no dejaron de presentarse en el espacio santafesino conductas que podrían ser concebidas como formas de disidencia cultural. Las prácticas y discursos alternativos que se manifestaron en los momentos de máximo control autoritario deberían ser pensados bajo la noción de Resistenz, ${ }^{3}$ captada específicamente con los matices de oposición, disidencia y divergencia, más que

\footnotetext{
1 Santa Fe entra en Argentina en lo que se caracteriza como ciudades de rango medio. La población del Departamento La Capital (Santa Fe y localidades cercanas), con indicación del porcentaje sobre la población total de la provincia, fue de 312.427 habitantes en el Censo 1970 $(14,63 \%)$ y de 381.449 en el Censo 1980 (15,47\%), siendo la población de la ciudad capital normalmente en torno a los tres cuartos del total (INDEC - Instituto Nacional de Estadísticas y Censos, http://www.indec.mecon.ar, consulta julio de 2011).

2 He propuesto una adecuación del concepto foucaultiano de "gubernamentalidad" y su aplicación a la zona santafesina, para referir a la limitación autoritaria de las conductas que no necesariamente supone su regulación por las agencias estatales, sino muy señaladamente por las relaciones cara a cara y por una impronta cultural conservadora (Alonso, 2011: 51 y ss.). Ello supone matizar la noción de una dominación pensada puramente desde los aparatos estatales y pensar una modalidad particular del poder vinculada a los procesos de subjetivación y articulada con el control de las poblaciones y el orden social. Una clarificación de las articulaciones entre distintas dimensiones y la postulación del nivel de la gubernamentalidad a escala local en Alonso (2015). La conceptuación de la gubernamentalidad se encuentra dispersa en distintos textos de Michel Foucault y es hasta variable, pero se puede apreciar más claramente en Foucault, 2006: 136.

${ }^{3}$ De acuerdo con Kershaw (2004: cap. 8), la noción de Widerstand -traducible al castellano como "resistencia" - estaría restringida a las conductas de rechazo fundamental y organizado al régimen, en tanto que la de Resistenz permitiría hablar de un amplio abanico de actitudes que deben ser incorporadas expresamente en la conceptuación de nuestra lengua. Supondría pues un universo de formas de rechazo parcial y limitado o de disidencia inorgánica, expresadas en una pluralidad de actitudes pasivas, acciones espontáneas, sentimientos y comportamientos. En el debate político argentino y en gran parte de la producción académica se utiliza -aun con estas connotaciones- el término "resistencia cultural", pero para evitar malentendidos respecto de la noción aquí defendida he preferido cambiar ese concepto por el de disidencia.
} 
bajo la lógica de una lucha política abierta, e incluso podrían ser entendidas como tensiones al interior de las clases medias ${ }^{4}$ (Alonso, 2017).

Teniendo en cuenta los estudios actuales sobre las relaciones entre campo cultural y poderes socio-políticos durante la última dictadura argentina, el presente texto tiene la intención de ampliar la perspectiva temporal y al mismo tiempo enfocar la mirada en algunos aspectos y agentes que permitan densificar el análisis a propósito de los desarrollos teatrales. La consideración de un período más amplio tiene por función postular un movimiento de conjunto que tanto pone en cuestión como afirma la excepcionalidad del último período dictatorial. Desde esta perspectiva, la consideración de un marco temporal extenso es necesaria para apreciar las similitudes y diferencias en momentos de diversas formas de gobierno, postulando paralelamente la continuidad del Estado y de una gubernamentalidad específica. Pero al mismo tiempo se propone profundizar el abordaje del caso local santafesino, partiendo de la idea de que la "institución teatro" adoptó allí relaciones equilibradas -en el sentido de formas más o menos estables y fijadas a un juego de restricciones y compensaciones- con otras instituciones y especialmente con las agencias estatales. Refiero aquí a la "institución teatro" por asimilación con la noción de “institución arte" de Herbert Marcuse, que supone la separación entre el arte y la vida, entre la esfera de la cultura y la reproducción material, o sea un carácter afirmativo de la cultura que quizás sea insuperable en el marco de las sociedades capitalistas (Marcuse, 1978; véase más adelante su recuperación en función de la lectura de Peter Bürger). En este nivel de caracterización, no se trata entonces de pensar la institución en términos de los tipos de compañías teatrales, las producciones o las relaciones intelectuales, artísticas y comerciales puntuales -que naturalmente son muy variadas-, sino como una forma general, concreta y estable, que adopta la obra de arte en la sociedad contemporánea. ${ }^{5}$

\footnotetext{
${ }^{4}$ Se entiende aquí por "clases medias" a los posicionamientos sociales que suponen situaciones intermedias en relación con la explotación y la dominación. Así, se engloba en esta categoría situaciones definidas por la propiedad de activos, sea en medios de producción, calificación u organización (Wright, 1989) o de ejercicio de autoridad o capacidad de acción delegada desde situaciones superiores (Müller, 1999). En términos de este último autor, determinados sectores socio-profesionales de las clases medias pueden ser definidos como "clases de servicio", distinguiéndose en su planteo tres grandes sectores: el de los servicios administrativos y comerciales, el de los servicios técnicos y profesionales y el de los servicios educativos y culturales. Por sus experiencias concretas en proximidad y vínculos a las personas para las que prestan servicios, este último sector sería más proclive que los otros dos a actitudes sociales solidarias o empáticas y a preferencias políticas progresistas o de izquierdas.

${ }^{5}$ En ese sentido, el teatro de los últimos años '60 no careció de experiencias que trataron de romper con la "institución arte" y establecer una reconexión entre arte y vida, aunque sea bajo la forma emparentada del happening (Baeza, 2017: 147-155). Pero claramente y más allá de que pueda predicarse el sesgo idealizado o utópico de esos intentos, el carácter no afirmativo de algunas producciones no dio lugar -o no podía dar lugar- a una puesta en cuestión exitosa de la "institución teatro".
} 
El movimiento de conjunto de la dinámica teatral santafesina podría ser esquematizado tomando como punto de partida el cénit de una etapa conocida en el ambiente artístico-literario de la localidad como una "época de oro", que hundiría sus raíces en la década de 1950 y culminaría abruptamente hacia los primeros años de la dictadura de la autodenominada "Revolución Argentina" (1966-1973). Luego vendría un segundo período cargado de experimentaciones y tensiones entre distintas opciones estético-políticas que atravesarían los finales de esa dictadura y todo el gobierno constitucional de 1973-1976, cerrado por la nueva dictadura del "Proceso" (1976-1983). El arco temporal se completaría con un tercer período que comenzaría a delinearse entre 1977 y 1979 -en el cénit de la última dictadura-, para asistir desde 1980 a un afianzamiento de una nueva generación teatral y del teatro independiente $\mathrm{o}$ neoindependiente, que desde ese entonces no cesaría de diversificarse y multiplicar las puestas en escena y cuyos desarrollos ulteriores caen fuera de los límites de este texto.

Complementando la consideración de ese arco temporal en la localidad, este trabajo esboza los trayectos seguidos por dos personas vinculadas con las experiencias del Teatro "Llanura", a los fines de dar cuerpo a la noción de la constitución de subjetividades disidentes por parte de individuos de las clases medias en ese complejo de articulaciones socio-políticas. En ese desarrollo, se recupera la noción de "comunidad teatral" -aplicada en Alonso, 2017- y se sugiere la conveniencia de recurrir al concepto de "educación sentimental" 6 para hablar de la formación de esas personas como miembros de dicha comunidad, categorías que en su amplitud permiten captar mejor que otras la plasticidad de los fenómenos bajo análisis.

\section{Cénit y abrupto final de una "época de oro"}

A nivel local, se forjó hacia la década de 1960 la concepción de Santa Fe como una ciudad particularmente activa en el plano artístico-literario, correlato del polo cultural que en el sur de la provincia representaba la ciudad de Rosario.

\footnotetext{
${ }^{6}$ Este concepto, de larga tradición con referencia a la formación de las personas en un medio afectivo, se deriva de la novela de 1869 La educación sentimental, de Gustave Flaubert. Debe recordarse que en ella el joven protagonista Frédéric Moreau no continúa sus estudios pero va transformando su personalidad en un entramado de relaciones afectivas -en su caso, acomodándose así a las circunstancias- (Flaubert, 2015). La educación sentimental puede ser conceptuada entonces como el proceso mediante el cual una persona internaliza comportamientos, definiciones de situaciones y concepciones del mundo gracias a su participación en un medio social y en un entramado de relaciones definidas principalmente por sus características emocionales. Como tópico literario o como concepto que da cuenta de un proceso interactivo no regulado de transformación de los individuos, no debe ser confundido con la educación emocional o sentimental en el sentido de un programa educativo específico basado en la psicología de las emociones.
} 
Una provincia que, al decir de José Pedroni -escritor devenido funcionario del gobierno de Aldo Tessio (Unión Cívica Radical, 1963-1966)-, poseía en ese entonces "luminarias del saber y del arte y templos de la cultura" (citado en Campana, 1999: 89). En ese marco de un campo cultural renovado en el que descollaban la experimentación en artes plásticas, la producción cinematográfica o la edición literaria, se sitúa aquello que se da en llamar la "época de oro" o de "apogeo" del teatro independiente santafesino (Ricci, 2005a). Desde la perspectiva de las políticas culturales provinciales, el espacio de las artes escénicas había recibido un fuerte acompañamiento con el gobierno de Carlos Sylvestre Begnis (Unión Cívica Radical Intransigente, 1958-1962), quien había dado apoyo a los elencos de teatro independiente (Logiódice, 2015). En 1959 la Dirección General de Cultura, a cargo de Francisco "Paco" Urondo, había creado un cuerpo de promotores culturales que tenían por función dinamizar las actividades del área en localidades del interior. Para 1963, en el gobierno de Tessio y con la gestión de Pedroni en el área provincial de Cultura se revitalizó el sistema de promociones culturales, se trató que las municipalidades asumieran tareas análogas en sus territorios y se desarrollaron en distintas localidades más de cien funciones de teatro de títeres (Campana, 1999: caps. V y VII). En la ciudad de Santa Fe, para ese momento, también se promovía el teatro desde la Universidad Nacional del Litoral (UNL), gracias al papel que en ese sentido cumplía en esas décadas José María Paolantonio (Ricci, 2005a: 472), quien -habiendo egresado de la carrera de Abogacía en 1954 y registrando tempranamente una profusa actividad literaria y dramatúrgicadesempeñó los cargos de Secretario de Cultura y Comunicación Social de la Municipalidad de Santa Fe (1958-1962) y de Director del Departamento de Extensión Universitaria de la UNL (1962-1968).

Pese a ese rol relevante de las reparticiones oficiales provinciales, municipales y universitarias, el espacio teatral local estaba ocupado en su casi totalidad por el "teatro independiente", ${ }^{7}$ conformado por elencos mayormente no profesionalizados e integrados por personas inscriptas en relaciones de clases medias, como puede apreciarse de sus perfiles socio-profesionales. Si bien puede ser discutible intentar clasificar a todos los elencos en la distinción oficial / comercial / independiente, es claro que los dos primeros términos de la ecuación eran minoritarios. Las tareas rentadas por los distintos niveles del

\footnotetext{
7 Se llamó así en Argentina al teatro surgido entre los años de 1930 y 1950 que no dependía de instancias comerciales o institucionales. Su emergencia rompió con la distinción entre profesionales y vocacionales, estableciendo una nueva diferenciación entre teatro comercial y teatro de arte. Desde los años ' 70 y sobre todo con posterioridad a la transición democrática, se podría hablar de un teatro neoindependiente, cuya cualidad distintiva es el intento de profesionalización y una constante experimentación o ausencia de formas consagradas de representación (Ricci, 2005b). Para Liliana Iriondo, el teatro neoindependiente seguiría dentro de la tendencia del teatro de arte, pero se caracterizaría por la autofinanciación y la búsqueda de subsidios para complementar los recursos para su sostenimiento (Iriondo, 1995).
} 
Estado eran ocasionales, limitadas a la contratación de promotores o directores y muchas veces objeto de carencias presupuestarias o incluso de su clausura en períodos de gobiernos de facto. Si bien algunas personas pudieron sostenerse económicamente aunque sea de forma parcial con una combinación de esos desempeños y la recaudación de puestas en escenas -con esporádicas subvenciones o préstamos de salas e insumos-, es difícilmente sostenible que esa actividad pueda ser catalogada de "comercial" asimilándola a las empresas teatrales porteñas. $Y$ esa cierta autonomía respecto de las instancias comerciales o institucionales iba acompañada del perfil típico del teatro independiente argentino, orientado a combinar la experimentación estética con obras de contenido socio-cultural crítico y con colectivos teatrales mayormente integrados por personas de idearios progresistas o de izquierdas.

Para mediados de la década de 1960 podría ya identificarse una cierta "comunidad teatral". Esta expresión, con todos los reparos que pueda suscitar por su carácter difuso, es probablemente más adecuada para referir a los individuos y colectivos inmersos en las especialidades escénicas que las nociones más estrictas de "campo" o "subcampo" debidas a la influencia de Pierre Bourdieu en la sociología de la cultura, en tanto es difícil definir un capital en juego y posiciones dominantes o pretendientes que lo estructuren. ${ }^{8} \mathrm{Si}$ bien es notorio el papel relevante de algunos directores locales abrumadoramente varones, propietarios, profesionales o funcionarios estatalescomo el citado Paolantonio, Israel Wisniak, Carlos y Alfredo Catania, Carlos Thiel, Miguel Flores, Carlos Pais o Rubén "Chiry" Rodríguez Aragón, debe señalarse el constante intercambio de roles en las diversas puestas en escena. ${ }^{9}$

\footnotetext{
8 Soy consciente de mi propia apelación ocasional a una noción de campo cercana a la idea de espacio social y geográfico de Bourdieu. Sin embargo y pese a la observación de ese autor en el sentido de que "Nociones tales como habitus, campo y capital pueden definirse, pero solamente en el interior del sistema teórico que constituyen, nunca en estado aislado" (Bourdieu, 1993: 1) hago uso de una acepción descontextualizada de su propuesta, en la cual el elemento definitorio no son las posiciones de los agentes sino sus relaciones, siempre en equilibrio inestable.

${ }_{9}$ De aquí en más la información sobre los agrupamientos, obras presentadas y datos personales proviene del relevamiento del Diario El Litoral, de autores como Zayas de Lima, 1990; Pellettieri, 2005; Ricci, 2012a; Schneider y Bucci, 2013 y Ramírez, 2016; de los sitios web Alternativa Teatral, Teatro del Pueblo y Asociación de Trabajadores del Estado (ATE), Santa Fe, Sección "Artistas Santafesinos" (http://www.alternativateatral.com, http://www.teatrodelpueblo.org.ar y http://www.ate.org, respectivamente); de blogs, linkedin y facebook personales (María Rosa Pfeiffer, Osvaldo Pettinari, Jorge Ricci, Julio Beltzer, Oscar Caamaño, Fabián Rodríguez, Mauricio Dayub), de los obituarios a Juan Carlos Rodríguez F, Matías Rodríguez y Jorge Delconte (Diario El Litoral, http://www.lt10.com.ar y similares); de las memorias de Florentino Sánchez en línea en www.sepaargentina.com.ar; de documentos oficiales de la Dirección General de Informaciones de la Provincia de Santa $\mathrm{Fe}$ y de folletos de obras de teatro depositados en el Archivo de la Memoria de la Provincia de Santa Fe (AMPSF) y de distintas entrevistas a Roberto Schneider (2011), a Jorge Ricci (2004, 2012b, 2014a y 2014b), y a María Rosa Pfeiffer (2017). Todas las consultas de sitios web de esta nota son de febrero de 2017. En tanto no se han encontrado mayores contradicciones en la triangulación de las fuentes, a los fines de
} 
Hay que destacar también la frecuente circulación de actores, directores y escenógrafos entre un grupo y otro, o las escisiones y combinaciones. Una misma persona podía participar de varios espacios teatrales al mismo tiempo y no era infrecuente la colaboración entre diversos agrupamientos o la extensión de la práctica de directores invitados.

Podría postularse también la participación de los distintos dramaturgos y actores en una cierta cultura de clase, por su pertenencia a las clases medias en un sentido amplio, aunque ese perfil cambiaría relativamente en el período. Aunque con inscripciones socio-laborales muy variadas, a mediados de los años sesenta destacaban propietarios de comercios (Israel Wisniak) o hijos de propietarios (Enrique Pasquini, escenógrafo y luego también propietario), locutores ("Chiry" Rodríguez), empleados públicos (Alfredo Catania). Ese perfil era congruente con el de otros varones que muchas veces llegaban a ejercer la docencia en esas áreas pese a tener formación en otros campos de conocimiento -muy particularmente en abogacía-. La formación y profesión docente parece ser más evidente entre las mujeres, algunas de las cuales -como Roma Mahieuadquirirían notoriedad más adelante. Y como suele suceder en ámbitos de experiencias compartidas, pueden reconstruirse distintas relaciones familiares o amorosas. Por ejemplo, en el Teatro de los 21, que tuvo un papel relevante en la primera parte de los años '60, se encontraba a los hermanos Carlos, Alfredo y Azucena Catania y algunos parientes como Olga Beatriz Martínez (esposa de Carlos), Gladys Elena Acebal (esposa de Alfredo) y Mario Jacobi (primo). ${ }^{10}$

Se lo defina como un subcampo o como una comunidad teatral, es claro que más allá de las evidentes diferencias entre uno y otro grupo sobre la forma de hacer teatro o la selección de obras existía en la zona santafesina un conglomerado de agrupamientos fluidos dedicados a la actividad, que pueden ser pensados más desde sus interrelaciones que desde sus posiciones relativas. Esa comunidad no estaba a su vez falta de fisuras, debates y especialmente discrepancias sobre los modos de su institucionalización. Desde 1963 se venían produciendo interrupciones en el funcionamiento de dos agrupamientos: la Asociación Santafesina de Teatros Independientes -afiliada a la Federación Argentina- y la Asociación Santafesina de Actores. La segunda tuvo un intento de revitalización en 1965, pero claramente no conseguía estabilizar su funcionamiento. Para marzo de ese año se realizó una asamblea en la sede del Teatro del Arte en la cual se consensuó una lista única. ${ }^{11}$ Pero las tensiones entre los distintos agrupamientos y personalidades fueron lo suficientemente fuertes

no interrumpir la narración se remitirá a las referencias correspondientes solo cuando se realicen citas textuales o que merezcan destacarse.

${ }^{10}$ Informe policial de 1964 reproducido en Informe de la Dirección General de Informaciones de la Provincia de Santa Fe en respuesta a Parte SIDE 15046 del 6 de septiembre de 1967, documento 182/67 (AMPSF).

${ }^{11}$ Diario El Litoral, 24 de marzo de 1965. 
como para que solo se llegara a una elección parcial del consejo directivo, con la continuidad de Carlos Thiel en la conducción, el reacomodamiento de varios nombres de la lista y el notorio reemplazo de Miguel Flores por Alfredo Catania en la función de Secretario General. ${ }^{12}$ La repercusión de esos colectivos se veía limitada por un medio social conservador, lo que se reflejaba en la escasa atención que la actividad teatral recibía por parte del medio de comunicación hegemónico a nivel local, el Diario El Litoral, pese a la benevolencia que encontraban en un crítico de teatro como Jorge Reynoso Aldao. ${ }^{13}$

El momento de 1965-1966 representaría quizás el cénit de esa época áurea, cuando en la ciudad se estrenaron 16 y 14 obras de teatro, respectivamente, por parte del Teatro del Sur, Teatro de Arte, Teatro Época, Taller de Teatro, Teatro Marcha, Grupo La Teja y otros agrupamientos como los de las localidades de Santo Tomé y Laguna Paiva, la Universidad Católica de Santa Fe y la Facultad de Ingeniería Química de la UNL. Pero luego de ese punto de máxima actividad, el ámbito teatral santafesino experimentó una crisis abrupta. En parte esa fractura había estado preanunciada por las tensiones anteriores y por la puesta en cuestión del modelo de teatro independiente, con la conformación de cooperativas teatrales a cargo de un director-empresario que contrataba personal para tareas precisas de actuación, escenografía, vestuario y demás. Esa idea de atribución de funciones más especializadas con un modelo más cercano al teatro comercial chocó con un medio social y político fuertemente limitado. Al decir de Jorge Ricci: “Los espectáculos generados por este sistema cooperativo fueron varios y estos trabajos resultaron ser el fruto y la coronación de toda una generación muy creativa que, en gran medida, era obligada a emigrar por una falta de mercado y una falta de apoyo oficial para profundizar en el oficio" (Ricci, 2005a: 484).

A eso debe sumarse el Golpe de Estado del 28 de junio de 1966, que supuso un quiebre para el campo cultural santafesino probablemente equiparable y en algunos aspectos superior a la fractura generada por la última dictadura. En lo que hace al ámbito teatral, su primer efecto fue la discontinuidad del sistema de promotores culturales y la clausura del Grupo de la Municipalidad de Santo Tomé, que en 1966 había realizado dos puestas en escena de Alfredo Catania. La carencia de recursos para el apoyo a los grupos teatrales se dejó sentir inmediatamente, mientras que el proceso de radicalización política que se producía introduciría nuevas tensiones al interior de la comunidad teatral.

\footnotetext{
12 Diario El Litoral, 18 de julio de 1965.

${ }^{13}$ La caracterización del periódico como medio hegemónico en Pisarello, 2013. El papel de Reynoso Aldao respecto de la promoción del teatro independiente fue destacado por Ricci (2005a: 483), en tanto que su rol al interior del diario puede apreciarse en Reynoso Aldao (2012).
} 


\section{Fisuras y crisis de la comunidad teatral, de una dictadura a otra}

El número de estrenos cayó notoriamente entre 1966 y 1971, comenzó a remontar tímidamente en 1972 y casi llegó a la decena de obras anuales entre 1973 y 1975. Es casi imposible no atribuir esa abrupta caída a las políticas de la intervención militar de 1966, así como a la migración de algunos exponentes relevantes como Roma Mahieu, Coco Leonardi, Alfredo Catania y Gladys Elena Acebal. Como estaba sucediendo en otras especialidades como la cinematografía o la literatura, se comenzó a producir un éxodo de aquellas personas más exitosas, ${ }^{14}$ sea a Buenos Aires, sea el exterior. En cierta medida la disminución de las puestas en escena fue parte del empobrecimiento general del campo cultural santafesino, en tanto que su posterior incremento paulatino puede vincularse con la emergencia de un teatro más firmemente político, en tensión con el teatro de arte que caracterizaba al modelo independiente. El repunte de las obras en 1973-1975 puede a su vez estar directamente vinculado con la actividad promotora del Estado y la recuperación de algunas políticas en ese sentido por parte de los gobiernos constitucionales provincial y municipal, pero como se verá es posible afirmar que eso no significó una alteración de las formas de estructuración del campo o de relación al interior de la comunidad teatral.

Los directores más reconocidos del momento eran personas como Wisniak, Rodríguez Aragón, Thiel, Pais y Catania, pero también cobró relevancia Juan Carlos Prete y progresivamente comenzaron a destacarse otros como Ricardo Gandini, Hugo Maggi y Jorge Ricci. De ellos, Carlos Thiel y "Chiry" Rodríguez eran quienes mayor cantidad de obras dirigían y tenían un claro reconocimiento en la comunidad teatral. Entre varios espacios de uso frecuente, los dos más relevantes parecen haber sido inicialmente el Teatro Cincel y el Teatro de Arte, ambos ubicados en la zona céntrica de la ciudad y sobre la principal calle comercial. El modelo de cooperativa no parece haberse consolidado, sino que se volvió a formas organizacionales más laxas y presentaciones bajo distintas identificaciones. A los grupos que llevaban los nombres de las salas Teatro de Arte y Cincel se pueden sumar otros como Estudio, Época, Ubú, Nueva Fábula y -sobre todo desde 1970 y en el marco de una mayor implicación de distintos espacios estatales y estudiantiles- elencos reunidos en el Liceo Municipal de Santa Fe, la Universidad Católica de Santa Fe, la Facultad de Ingeniería Química y espacios similares. Pero el colectivo que mejor puede representar las innovaciones estéticas y las tensiones del período es quizás el Grupo 67.

\footnotetext{
14 Tomando como ejemplo el ámbito de las letras, en la década de 1960 habían migrado los escritores Francisco Urondo, Eduardo Gudiño Kieffer y Juan José Saer. También se había alejado y luego fallecido Luis Gudiño Krámer, quien había sido secretario de redacción del diario El Litoral.
} 
Pese a que en los años anteriores ya se verificaban experiencias vanguardistas y neovanguardistas y una tendencia a reemplazar el estreno de obras consagradas de autores extranjeros por textos escritos en la propia ciudad, fue en este período donde se completó el paso a nuevos modos de hacer teatro y a algunos intentos de romper la distinción entre arte y vida, poniendo en cuestión con obras no afirmativas aquello que puede denominarse la "institución teatro" (véase nota 5). Por un lado, fue en declive la influencia del método interpretativo de Konstantín Stanislavski; por el otro, creció en la comunidad teatral santafesina el recurso al absurdo, probablemente como modo de esquivar las restricciones políticas imperantes. En el Grupo 67 es donde mejor se puede apreciar ese cambio, ya que en su conformación se dejó sentir la influencia de los postulados del "teatro pobre" de Jerzy Grotowski, que suponían un alejamiento de los cánones del momento. ${ }^{15}$ La forma de hacer teatro de ese grupo se consolidó en una experiencia colectiva que -en la tónica de la definición de vanguardia de Peter Bürger (2010)- parecía romper la distinción entre arte y vida. El colectivo se instaló durante un par de años en una casa y comenzó una experiencia de vida comunitaria en la cual todas las noches se hacían sesiones de improvisación y estudio (Ricci, 2005a: 492, nota 6). Otra vez, en la constitución de los agrupamientos tenían importancia los vínculos parentales, pues entre las ocho personas que vivían efectivamente en ese domicilio -a las que se sumaban otras para las actividades teatrales- se registraban tres matrimonios. La experiencia del 67 fue innovadora en términos estéticos y comunitarios, pero a su vez fue tachada de "elitista" por otras personas del medio teatral más comprometidas con la política partidaria (Ramírez, 2016: 97). Cuando a raíz de una intervención policial poco clara una parte del grupo fue detenido y encarcelado en agosto de 1971 sus integrantes aún vivían en una "casa abierta" y con ciertos rasgos comunitarios, pero la experiencia ya se venía diluyendo desde dos años antes y varios de los integrantes habían seguido otros caminos, en los cuales la "institución arte" (en los términos de Herbert Marcuse recuperados por Bürger, 2010) no parece haber sido puesta en cuestión tan radicalmente.

En paralelo con esas tendencias, hubo en el período un cierto reacomodamiento de las acciones oficiales. La discontinuidad de las promociones culturales y de teatros municipales se vio en cierta medida compensada por la permanencia de la subvención a teatros de títeres -con elencos ocasionales y no integrados a las plantas de personal-, por la continuidad de los apoyos a diversas puestas en escena -que a veces se puede apreciar en la realización de afiches y programas por la Imprenta Oficial de la

\footnotetext{
${ }^{15}$ Sobre los postulados del teatro pobre véase Grotowski (1992); el original inglés es de 1968 y el artículo que da nombre al volumen de 1965.
} 
Provincia, lo que llamaba la atención de los servicios policiales- ${ }^{16}$ y por un programa especial provincial de Teatro para Sordos. En ocasiones, los vínculos con otros niveles del Estado como ser las embajadas, posibilitaron viajes como el del Grupo 67 no solo a países como Francia, Italia y Estados Unidos, sino también a Checoslovaquia y Polonia (Ramírez, 2016: 100). ${ }^{17}$ También se fueron ampliando los espacios para las puestas en escena y en 1970 se modificó el antiguo foyer del Teatro Municipal para conformar una nueva sala que pronto sería usada por muchos agrupamientos. ${ }^{18}$

Con el cambio de los gobiernos provincial y municipal en 1973, tras el triunfo del Frente Justicialista de Liberación, las políticas de apoyo a la actividad teatral se orientaron a la creación de compañías oficiales. Sin embargo, para la ciudad de Santa Fe los únicos hechos relevantes fueron la mayor institucionalización de un espacio formado durante el anterior gobierno militar con la creación del Elenco Provincial del Teatro de Sordos, en relación de dependencia directa con el Ministerio de Educación y Cultura del Gobierno de la Provincia por Ley N 7.351 de 1974 y la contratación regular de personal para un Elenco Estable de Muñecos, ya que la Comedia Provincial Santafesina se localizó en la ciudad de Rosario. ${ }^{19}$ Interesa entonces destacar que entre la última etapa de la "Revolución Argentina" y el período constitucional posterior no parece haberse producido una modificación sustancial de las formas de distinción de diversos espacios teatrales y ni de los modos de intervención de las agencias estatales, excepción hecha de los intentos justicialistas de 1973-1975 por promover un teatro popular a través de elencos oficiales.

La comunidad teatral santafesina estaba por entonces atravesada por las tensiones entre un teatro más orientado por imperativos estéticos y otro más vinculado con posicionamientos partidarios. Como lo ha demostrado Paula Ramírez (2016: 96-102), el teatro presentó heterogeneidades específicas, con un conjunto de agentes individuales y colectivos impactados por la cultura hippie y la emergencia de otros agrupamientos vinculados a o simpatizantes con el peronismo de izquierda, que denunciaban las tendencias "extranjerizantes". A

\footnotetext{
16 Informe citado de la Dirección General de Informaciones (DGI) en respuesta a Parte SIDE 15046, en la sección "Otros datos de interés", AMPSF

${ }_{17}$ Algunas actrices y actores santafesinos habían viajado en anteriores momentos para formarse en los países de Europa del Este, en tanto que en los informes de la DGI obrantes en el AMPSF se nota la preocupación por el conocimiento de las actividades de viajeros o migrantes procedentes de esos países, de quienes eran garantía de sus visas o de las personas que viajaban hacia allá.

18 Esa Sala del Teatro Municipal " $1^{\mathrm{o}}$ de Mayo" de Santa Fe recibiría luego el nombre de "Leopoldo Marechal". Con unas 200 butacas, es muy inferior a las 800 de la Sala Mayor y por ello más apropiada para obras de teatro independiente. Una tercera sala, más pequeña y en los altos de la misma ala del teatro, también fue usada en adelante para representaciones teatrales. 19 Sobre las acciones del período y el organigrama de las áreas provinciales de Cultura, véase Campana (1999) y Logiódice (2015).
} 
su vez, el abandono que Ramírez registra de algunos autores paradigmáticos del período anterior, como Bertold Brecht, puede deberse a la decadencia de las relaciones del medio artístico santafesino con el Partido Comunista y al predominio de otras identidades políticas. ${ }^{20}$ En gran medida esas tensiones suponían distintas lecturas de lo que resultaba disruptivo o de avanzada. Para algunos colectivos y personas, la capacidad de subversión estaba dada por las mismas definiciones estéticas; para otros, por la adopción de un discurso contencioso mayoritariamente pensado en la matriz política del peronismo. Pero a su vez esa distinción corre el riesgo de ser esquemática, pues entre unas y otras posiciones se pueden apreciar solapamientos, como en el caso particular de Rubén Rodríguez Aragón.

Otro elemento que atravesó los momentos dictatorial y constitucional fue el interés de las agencias de información estatales por el control de las actividades teatrales. Ello, pese a que la mayor parte de quienes integraban la comunidad teatral santafesina no registraban para la Dirección General de Informaciones de la Provincia antecedentes policiales, judiciales, políticos o ideológicos. En general se los consideraba carentes de "antecedentes peligrosos", aunque a veces se destacaba el hecho de que personas de mayor edad hubieran estado afiliadas al Partido Peronista a inicios de los años '50 y que de otras se tuvieran sospechas respecto de sus vínculos con integrantes de organizaciones de izquierda o agrupaciones armadas. Sobre todo, las suspicacias de las reparticiones de inteligencia no llevaron a una ruptura de los vínculos entre el ámbito teatral y las dependencias estatales del área de la cultura, que siguieron siendo de relativa importancia para asegurar cierto apoyo a las distintas puestas en escena.

Probablemente un aspecto mucho más relevante para las limitaciones en el éxito de público fuera la gubernamentalidad autoritaria local, en la cual los artistas eran objeto de una estigmatización de carácter conservador. Al decir de Campana, al menos para las autoridades municipales muchas de las personas involucradas en el ámbito artístico eran catalogadas inmediatamente de "izquierdistas", "afeminados" o directamente de improductivos (Campana, 1999: 82), calificaciones que justificaban la retracción de las ayudas. En ocasiones, los controles del comportamiento cotidiano se unían a las restricciones políticas, como en el caso de la expulsión de la Escuela Provincial de Artes Visuales "Profesor Juan Mantovani" del titiritero y actor Florentino Sánchez en 1969, cuando era presidente del centro de estudiantes. Más ampliamente, es posible postular una más difusa pero no por ello menos efectiva limitación del medio social en general y de espacios de clases medias en particular, perceptibles tanto en la relativa ausencia de muchas actividades en el

${ }^{20}$ Correlativamente, en los informes de la DGI es visible hacia los años de 1968-1970 el paso de la preocupación por el seguimiento del Partido Comunista Argentino a las agrupaciones armadas o "subversivas" (AMPSF). 
diario El Litoral como en la denuncia de un vecino que motivó el allanamiento a la "casa abierta" del Grupo 67 en 1971 (Ramírez, 2016: 101).

En ese contexto, los espacios universitarios y en general los educativos brindaron -pese a sus vaivenes- la posibilidad de socialización y formación artística de integrantes de las clases medias. Podría decirse incluso que en este momento comenzó una variación en las inscripciones de clase, con un progresivo predominio de personas de la clase de servicio en su sector de servicios culturales (véase nota 4), ya que los pequeños propietarios, empleados públicos y abogados serían reemplazados por profesores de letras o de artes plásticas, ampliándose a los varones la cualificación docente antes solo dominante entre las mujeres que hacían teatro. Es notoria la importancia creciente de actores y actrices que cursaron estudios en el Instituto del Profesorado Básico de la Universidad Nacional del Litoral, transformado en 1970 en Escuela Universitaria del Profesorado, al tiempo que el Instituto de Cine de la UNL y la citada Escuela Artes Visuales comienzan a aparecer más frecuentemente en noticias de prensa y testimonios relativos al espacio teatral santafesino.

Con su debilidad relativa respecto de la supuesta "época de oro" anterior y con las tensiones propias de un ámbito cultural y una comunidad heterogéneas, la actividad teatral santafesina se fue afianzando a inicios de los años de 1970. Crecía el número de obras estrenadas, muchas de ellas con guiones propios, y directores como Carlos Thiel conseguían insertarse en un circuito de presentaciones nacionales e internacionales. Mantuvieron continuamente actividad los teatros de títeres y creció el espacio del teatro infantil, formándose en 1972 el agrupamiento Los Mamelli, dirigido por Hugo Maggi. ${ }^{21}$ Se diversificaban las opciones estéticas y aparecían nuevos elencos, entre los que comenzaba a destacarse un grupo formado por Ricardo Gandini y Jorge Ricci que luego de poner en escena en 1972 La llanura estremecida escrita por el segundo, bajo la efímera denominación de Teatro Mandala, devendría en el Teatro Llanura. Se estrenaban obras políticamente comprometidas, como El avión negro de Cossa, Rozenmacher, Somigliana y Talesnik por "Chiry" Rodríguez, Miguel Flores y Felipe Cherep en 1971 o como Sacco y Vanzetti de

21 Los Mamelli tendrían una dilatada e ininterrumpida experiencia claramente intergeneracional, con formaciones cambiantes por las que pasaron Hugo y Osvaldo Maggi, Raúl Farías, Paco Hase, Mónica Bono, Cocho Maragno, Lina Volpogni, Adriana Cornú, Eduardo Pascucci, Carlos Deb, Ricardo Llusá, Mónica Moreno, Silvana Montemurri, Maga Malvicino, Pati Malvicino, Nelly Giscafré, Patricia Moreno, Mario Culasso, José Luis Volpogni, Silvia Paredes, Alicia Belucci, Alicia Naput, Marta Coutaz, Susana Fuentes, Carlos Thiel, Osvaldo Pettinari, Juan Carlos Rodríguez, Fernando Collados, Martín Sosa, Benjamín Sosa y Agustín Posentini (http://gobierno.santafe.gov.ar/prensa, noticia del lunes 15 de agosto de 2011 150811s11.htm, consulta de febrero de 2017). Hay que contar también entre ellos a Luis Maragno, no registrado en el listado antes citado pero visible en las noticias periodísticas del grupo en el último período dictatorial. 
Rolli y Vicenzoni por Carlos Thiel en 1973. Por fin la institucionalización de elencos por parte de los gobiernos provincial y municipal justicialistas, aunque dispar, permitió sobre el final del período sostener económicamente a actrices y actores de teatro y de títeres.

Esa fue sin dudas una etapa de tensiones sociales y políticas crecientes, con los primeros esbozos de una represión sangrienta mientras se renovaban las partidas hacia el exilio. Pero el Golpe de Estado de 1976 supuso una fractura de tal envergadura que es posible postular para ese momento el fin del ciclo de afianzamiento y una reconfiguración posterior de la comunidad teatral santafesina.

\section{La reconfiguración del ámbito teatral entre la dictadura a la democracia}

La última dictadura supuso una limitación de las obras y de los autores posibles de ser representados. La correlativa retracción del espacio de exhibición se tradujo en el estreno de apenas tres obras independientes en 1976, al tiempo que se restringió la participación oficial en el ámbito teatral en comparación con el gobierno constitucional anterior. En 1976 se clausuraron la Comedia Provincial y un Taller Laboratorio teatral, y en 1978 el Elenco Estable de Muñecos. ${ }^{22}$

Sin embargo, ya en 1977 hubo más actividad teatral independiente que bajo el gobierno constitucional, lo que probablemente pueda interpretarse como una compensación frente a la clausura de espacios oficiales. También se observa la progresiva aparición de nuevos nucleamientos y la ampliación del espacio del teatro en la localidad. De las experiencias de 1973-1975 solo se discontinuó la del Grupo Alpha, dirigido por Ricardo Ahumada, si bien de ello no debe inferirse que las personas que lo integraban no continuaran en otros ámbitos. ${ }^{23}$

Los únicos grupos que estrenaron obras sin interrupciones incluso desde 1976 y hasta 1983 fueron Los Mamelli dirigido por Maggi, el agrupamiento dirigido por Osvaldo Neyra aparecido alternativamente con las denominaciones de Cuatro Tablas, Grupo Talía y Teatro de la Casa del Maestro, y el Teatro Llanura dirigido por Ricci. Pero desde 1977 comenzaron a aparecer muchos otros agrupamientos o a revitalizarse denominaciones anteriores, como ser el Teatro Estudio, el Teatro de Arte, el Pequeño Teatro, el Teatro Arena, Nuestro Teatro, el Teatro del Actor que luego dio lugar al Teatro Taller, el Grupo de Actores y el Grupo Yankó. A veces incluso resulta dificultoso definir un elenco o grupo teatral concreto en una puesta en escena, ya que aparecen

${ }^{22}$ Es interesante destacar que la clausura de esos espacios no fue abrupta. Por ejemplo, para 1977 se renovó el Elenco de Muñecos con personal contratado, que no fue convocado ya al año siguiente (Pfeiffer, 2017).

${ }^{23}$ Ricardo Ahumada no fue incluido en las cesantías de 1974-1976 en la UNL y siguió desempeñándose como profesor de varias materias de arte y literatura en la Escuela Universitaria del Profesorado. En el período 1979-1981 apareció vinculado al Grupo de Actores. 
con distinta denominación en los registros, en función de la dinámica de entrecruzamientos y escisiones a la que se hizo antes referencia y a las prácticas de los directores invitados. ${ }^{24}$ Contabilizando solo las producciones encuadrables en "teatro independiente" -con todas las salvedades antes enunciadas- y dejando de lado las obras realizadas en instituciones educativas de variada dependencia, entidades benéficas o asociaciones vecinales, podría hablarse de un promedio de ocho o nueve puestas en escena por año.

La mayor vitalidad del ámbito teatral podría cifrarse de 1979 en adelante. Hugo Maggi, que llegó en 1980 a la Sala Mayor del Teatro Municipal con Inodoro Pereyra, montaría en 1983 el espectáculo musical Canciones para Mirar de María Elena Walsh; mientras que el director Raúl Galoppe haría lo mismo con Decadencia Divina de Mary Canca. En julio de 1981 Roberto Lemes dirigió Abran cancha, que aquí viene Don Quijote de la Mancha, de Adela Basch, bajo el sello de Cuatro Tablas. Por su parte, entre los años de 1978 y 1980 el Núcleo Teatral Talía dirigido por Osvaldo Neyra, presentó tres comedias siguiendo una secuencia de géneros: La cantante calva de Eugene Ionesco (humor absurdo), El médico a palos de Moliére (humor satírico) y Cuento de la hora de acostarse de Sean O'Casey (humor burlesco). Aunque en estos casos se trataba de clásicos, tanto en ellos como en los anteriores las obras apuntaban más al divertimento. Si bien podían presentar aspectos disruptivos desde la perspectiva de un medio social mayormente conservador, no se apreciaría en ellas ninguna tendencia política clara.

Pero otros elencos de teatro independiente fueron presentando puestas en escenas novedosas y hasta transgresoras. El primero fue el Teatro Llanura, que al mismo tiempo que buscaba un lenguaje teatral propio se alejaba de los clásicos internacionales y buceaba en temas que resultaran significativos con obras de cómo Mustafá, de Armando Discépolo (1977) u otras escritas por el mismo Ricci, con la colaboración autoral y actoral del Teatro Arteón de Rosario, o más tarde adaptaciones de Roberto Arlt -El Jorobadito, 1981- y Juan José Saer Verde y negro, 1983-.

El Grupo de Actores dirigido por Antonio Germano, osciló en esos años entre las representaciones tragicómicas en la tradición argentina del grotesco y el sainete, y los dramas de autores clásicos. En 1979 estrenó El abanico de Venecia, de Juan Carlos Ghiano, y al siguiente Cómico, una pieza de Germano dedicada a

24 Por ejemplo, Osvaldo Neyra y un grupo variable aparecieron en montajes bajo la denominación de Cuatro Tablas. Posteriormente, bajo ese nombre se montaron obras con la dirección de Roberto Lemes y Neyra conformó el Grupo Talía, aunque luego también apareció en el Teatro de la Casa del Maestro. Por otra parte, la Cooperativa Teatral de Maggi no aparece mencionada con ese nombre con posterioridad a 1977, pero Ricci (2005a: 445) la identifica con la reposición en 1980 de Inodoro Pereyra, el renegau, obra basada en textos del rosarino Roberto Fontanarrosa que Maggi ya había estrenado en 1974 y que se continuaría presentando con éxito en temporadas subsiguientes. 
la trayectoria artística de Pablo Podestá. Tanto esas obras como Macbeth de William Shakespeare en 1981, Rockyfeller en el lejano oeste de Rene de Obaldía en 1982 y Todos eran mis hijos de Arthur Miller en 1983 se presentaron en el Teatro de la Biblioteca Moreno, mientras Germano sería también mentor del Grupo Estable de Rafaela y de otro en la Alianza Francesa de Santa Fe.

Para 1980 cobraron relieve también dos nucleamientos en los que tenían participación destacada Jorge Conti y Ricardo Gandini: Nuestro Teatro que presentó La Biunda de Carlos Carlino, con dirección de Conti y Juan Carlos Rodríguez F., y el Teatro Arena donde Gandini montó El Cine de Enrique Wernicke. Este último fue también director de la Escuela de Actores del Arena, en cuya sala propia daba clases de historia del teatro Conti y ensayaban otros elencos. Por fin, comenzaron a aparecer obras dirigidas por Julio Beltzer, más joven que los anteriores y que recién culminaría sus estudios de Letras en este período. Con el Teatro del Actor y la colaboración de Daniel Machado había presentado en 1978 Final de Partida de Beckett y en 1980 En Altamar de Mrozek.

Para el período central de la dictadura, entonces, el peso de la actividad teatral era otra vez muy fuerte. Los distintos grupos llegaron a conformar una Coordinadora que organizó desde 1979 Muestras Nacionales en el Municipal de Santa Fe, en vínculo con distintas entidades como la Sociedad de Bioquímicos, la Federación Argentina de Trabajadores de Teatro Agremiados, la Fundación Arcien y distintas casas comerciales. Pese a esa clara inserción en el contexto institucional santafesino, la Coordinadora de Teatro no dejaba de suscitar suspicacias en la Comunidad de Inteligencia del Área $212,{ }^{25}$ ya que aunque ninguna de las obras fuera en rigor "teatro político", muchas de ellas criticaban la moral dominante o el ejercicio del poder. Los concurrentes, cuyo perfil estudiantil no pasaba desapercibido para las entidades policiales, eran minuciosamente contabilizados. ${ }^{26}$

Algunas situaciones de inserción institucional y vigilancia policial muestran la complejidad de las relaciones de poder en el campo cultural. Mientras unas agencias estatales controlaban la actividad teatral y calificaban como potencialmente peligrosos a distintos agentes individuales o colectivos, otras les facilitaban la presentación de sus obras (Alonso, 2017). Es precisamente el caso del Teatro Municipal, que bajo la dirección de Jorge Terpin dio una

\footnotetext{
${ }^{25}$ Nota del Jefe de Departamento de Inteligencia 122 del Ejército Luis Alberto González, del 20 de mayo de 1980, convocando a reunión del 3er. Nivel de la Comunidad de Inteligencia (AMPSF).

${ }^{26}$ Por ejemplo, en 1979 se registraron 2.859 personas para la asistencia a diez obras, según informe sin firma sobre la Muestra Nacional de Teatros realizada del 7 al 14 de octubre de 1979, Dirección General de Informaciones de la Provincia de Santa Fe, en respuesta al Mensaje 32181 del 16 de octubre de 1979 (AMPSF).
} 
amplia acogida a los grupos independientes. ${ }^{27}$ Para el período 1981-1983 varios elencos se encontraban en una situación ambivalente: por un lado expresando ideas que podían ser consideradas disidentes o hasta "subversivas" por los poderes estatales, y por el otro integrándose en un complejo de acciones y colaboraciones con las mismas autoridades dictatoriales, que siguiendo la tónica habitual de las reparticiones oficiales les brindaban apoyos económicos, les facilitaban salas o les permitían apariciones en prensa. Tal vez, la situación descripta podría ser interpretada como "transicional".

Obviamente, lo que se puede denominar la gubernamentalidad autoritaria santafesina se vio encuadrada y reforzada por los procesos de control y represión estatal durante la última dictadura. Pero también es correcto apreciar que sobre el final de ese período la apertura política se expresó en una multiplicación de las obras críticas, que además de las producciones clásicas y de las propias ya incluían piezas de Eduardo Pavlovsky (Teatro Llanura), Roberto Cossa (Grupo de Actores) o Aída Bortnik (Grupo Thalía). A partir de ese momento se apreciaría un proceso de reinstitucionalización de la cultura ${ }^{28} \mathrm{y}$ una clara democratización del campo cultural.

\section{Dos trayectos individuales, o la educación sentimental de las clases medias}

De las múltiples experiencias individuales registradas en el espacio santafesino en un arco temporal tan amplio, interesa aquí esbozar dos casos para una demostración de las tensiones que involucraban a la comunidad teatral y a la producción en un contexto complejo de aquello que podemos denominar "subjetividades disidentes". Se trataría en este caso de formas de articulación entre el mundo interno de las personas y sus referencias ideológicas y psicológicas, con sus acciones externas o comportamientos -es decir, una concepción del sujeto como totalidad-, que presenta discrepancias, fracturas o conductas desviadas dentro de lo hegemónicamente normativo en una sociedad. En estos casos no podríamos hablar de oposiciones políticas e ideológicas fundamentales, sino que más bien podríamos encontrar conductas no convalidadas por los poderes públicos o las opiniones dominantes, actitudes pasivas, acciones espontáneas o sentimientos externalizables que podemos identificar con la Resistenz.

\footnotetext{
${ }^{27}$ Esa actitud fue más tarde reconocida por directores como Ricci, para quien la de Terpin fue "tal vez una de las mejores gestiones que hubo en el teatro" (Ricci, 2014a) o Germano, quien declararía que "nos abrió la puerta, cuando las puertas estaban cerradas para nosotros" (Germano en Schneider y Bucci, 2013: 67). Terpin también jugaba un papel importante en la difusión de las actividades culturales, concurriendo a entrevistas en El Litoral y seguramente también en las radios locales. La secretaria del Teatro Municipal era en esos momentos una persona íntimamente vinculada a la actividad teatral: Silvana Montemurri (Pfeiffer, 2017).

${ }^{28}$ La expresión es de Logiódice (2015: 87), aplicada al ámbito del Estado provincial. Ello también es notorio respecto de entidades estatales autónomas como la UNL.
} 
Resulta oportuno revisar aquí la trayectoria de dos integrantes del Teatro Llanura, cuyas acciones no pudieron desgajarse de la "institución teatro" pese a momentos de producción de obras con un sentido no afirmativo y que no tuvieron acciones de oposición político-ideológica ante los distintos gobiernos constitucionales o dictatoriales, pero que expresaron de una $\mathrm{u}$ otra manera fisuras tanto respecto de las tendencias dominantes a nivel estatal como respecto de la gubernamentalidad autoritaria local-regional. El primero es uno de sus creadores y luego director durante décadas, Jorge Ricci, y la segunda una actriz que pasó entre los años de 1980 y 1983 por la agrupación, María Rosa Pfeiffer. El acercamiento a estos casos permite apreciar dos trayectos formativos diversos, correspondientes a generaciones distintas -mientras Ricci permite barrer todo el arco temporal de este escrito Pfeiffer sólo aparece sobre el final de la última dictadura-, unidas en la disidencia al poder autoritario. Podría postularse que las dos personas aludidas registraron experiencias muy diferentes, pero al mismo tiempo articuladas en un medio social, educacional y artístico que les posibilitó construir posicionamientos no menos complejos que los de su entorno.

Jorge Ricci vivió siempre en las ciudades de Santo Tomé y Santa Fe, e inició sus actividades teatrales en el elenco de la municipalidad de la primera ciudad dirigido por Alfredo Catania que fue desarticulado tras el Golpe de Estado de 1966. Estudiaba Literatura en el entonces Instituto del Profesorado Básico de la UNL, donde conoció a quien sería su esposa, María Delia Fernández. Se incorporó con veinte años a la experiencia del Grupo 67 y con él accedió tanto a la propuesta del "teatro pobre" de Grotoski como a la eliminación de la distancia entre arte y vida que se proponía con la vida comunitaria.

En 1968, a propósito de un pedido de la Dirección General de Informaciones de la Provincia a la Secretaría de Inteligencia del Estado la primera de esas reparticiones indicaba que se tenía "fundada sospecha sobre su ideología". ${ }^{29}$ De todo el Grupo 67 -que en esos momentos presentaba en la ciudad de Buenos Aires Historias para ser contadas de Osvaldo Dragún y La extraña tarde del Dr. Burke de Ladislav Somcek- Ricci era el único sobre el que se dudaba de sus antecedentes y vínculos. En esa pieza él estaba a cargo de la musicalización, pero prontamente, luego de crecer actoralmente y de una serie de experiencias compartidas con Ricardo Gandini -también del Grupo 67formó el equipo del cual saldría el Teatro Llanura. En 1972 presentaron El nitrógeno de Obaldía y La llanura estremecida del propio Ricci, pero la obra que cimentaría su fama en el medio local e instalaría la denominación del Teatro Llanura fue el montaje de Woyzeck de Georg Buchner, en la Sala Marechal. Ese

\footnotetext{
29 Informe de la Dirección General de Informaciones de la Provincia de Santa Fe en respuesta a Parte SIDE 26629 del 12 de diciembre de 1968, documento 115/68 (AMPSF).
} 
éxito se repetiría en 1974 con Ubú Rey de Jarry y en 1975 De Chéjov con humor, sobre textos del autor ruso.

Para ese momento, Ricci comenzó a insertarse en talleres de teatro de clubes y municipalidades, desempeñándose también como director invitado. En 1975 el Equipo Llanura ya estaba consolidado y abrió una escuela de actores y técnica teatral en la Biblioteca "Mariano Moreno". Integraban el grupo en ese entonces el mismo Ricci, Jorge Conti, Cristina Telesco, Ricardo Gandini, Rubén Varela, Pete Cánaves, Carlos Falco, María Delia Fernández, Estela Curi y Marina Vázquez. Las primeras cuatro personas figuraron en distintas publicaciones como profesores o directivos de la escuela de teatro ${ }^{30}$ y las asignaturas iniciales fueron Formación del Actor, Teoría Teatral, Historia Social del Teatro y Expresión Corporal. Muchos de los integrantes del elenco habían estudiado Letras y en el caso de Falco Arquitectura, en tanto que al menos Fernández y Vázquez estaban emparentadas por consanguinidad, y casadas a su vez con Ricci y Falco.

Con esa escuela las perspectivas de Ricci y Conti tuvieron un innegable impacto en el medio teatral santafesino. Por ese espacio pasaron muchos de los integrantes de los elencos que se fueron formando a posteriori y el Llanura sufrió varias escisiones e incorporaciones en 1975-1977, que su conductor recordaría más asociadas a las discusiones sobre las opciones teatrales o incluso a "problemas de polleras" (sic) y no relativas a diferencias políticas (Ricci, 2014b). Las agencias de seguridad lo controlaban, ${ }^{31}$ aunque él planteara no haber sido consciente de ello: "Me parece a mí que no estábamos siendo observados. A lo mejor éramos observados y yo no lo sé" (Ricci, 2014b). Pero al mismo tiempo podía presentar sus obras sin inconvenientes y sin censura previa, probablemente porque -en sus palabras- "el teatro de arte que hacíamos nosotros era una cosa de cofradía y entonces evidentemente no alcanzaba a la preocupación de [las autoridades por] lo que podía ser la música popular, el cine" (Ricci, 2014b). ${ }^{32}$

\footnotetext{
${ }^{30}$ V. g. en El Litoral, 2 y 8 de febrero de 1975, pp. 10 y 7 respectivamente.

31 Por ejemplo, Parte SIDE 7982 del 27 de agosto de 1979 a Delegaciones Provinciales, que solicitaba información, entre otros, de los teatros existentes con indicación de propietarios de las salas, tipo de obras, autores, actores, responsables, "ideología", etcétera (AMPSF).

${ }^{32} \mathrm{He}$ analizado la tolerancia de las autoridades dictatoriales con la puesta en escena de obras que podían entenderse como críticas respecto del orden imperante en Alonso, 2017. Sin dudas, el carácter limitado del teatro en términos de público e impacto mediático -muy distinto del que tenía el cine, la televisión, la prensa gráfica o los espectáculos musicales- jugó a favor de una menor censura y persecución. Para el caso de la ciudad de Buenos Aires, destacaron distintas salas de tamaños reducidos que representaban obras con evidente contenido social o posibilidades de lecturas políticas. Incluso con la observación de que una censura directa e indirecta sobre autores como Bertold Brecht, Osvaldo Pellettieri registra una continuidad de las representaciones de sus obras en el Teatro del Centro o en el Espacios, así como en las salas menores de entidades judías como IFT y la Sociedad Hebraica Argentina (Pellettieri, 1994).
} 
Tras el Golpe de Estado de 1976 experimentó en persona las ambivalencias del poder dictatorial: fue cesanteado en un cargo público pero no en otro que mantuvo sin inconvenientes, mientras su esposa María Delia sí fue declarada cesante en todos sus cargos y horas de cátedra. Paralelamente, comenzó a dirigir piezas del Teatro del Liceo Municipal de Santa Fe y en 1978 fue llamado para dirigir el Teatro para la Salud, iniciativa de las autoridades dictatoriales provinciales tendiente a establecer mecanismos de control de las conductas (Schenquer, 2016). Situación paradojal, pues para la Comunidad de Inteligencia era potencialmente peligroso y se destacaban sus "relaciones con elementos del PST" (Partido Socialista de los Trabajares) y anteriores vinculaciones con otros grupos de izquierda. ${ }^{33}$

En 1976 el Llanura montó Escorial de Michel de Ghelderode, en 1977 El Debut de la Piba de Roberto Cayol y Mustafá de Armando Discépolo, en 1978 Sueño de Juventud de Ricci y en 1979 Lágrimas y Sonrisas, de González, Castellano y Ricci, estas dos últimas en colaboración con equipos rosarinos. Entre el final de los '70 e inicios de los '80, Ricci estaba buscando elaborar un lenguaje teatral propio y desarrollar contenidos que no fueran mera imitación de los grupos de Buenos Aires. Un intento en ese sentido fue la obra Zapatones, que recurriendo a formas propias del circo presentaba la historia de un cómico acompañado por un chico tramoyista interpretado por María Rosa Pfeiffer. Se estrenó en junio de 1980 en la Sala Marechal ${ }^{34}$ y recibió críticas elogiosas: "Deliberado ejercicio para actor y acompañante, 'Zapatones' concita el desafío que Ricci-autor ha lanzado a Ricci-actor. Haber salido airoso de su propia propuesta es tal vez la mejor gratificación de su carrera" ${ }^{35}$

De las muchas obras presentadas por el Teatro Llanura durante la dictadura, El Jorobadito fue sin dudas la que más repercusión parece haber

Obras de más envergadura como los dramas musicales "Aquí no podemos hacerlo" de 1978 o "Calígula" de 1983, dirigidas por Pepe Cibrián Campoy, representarían ejemplos de discursos disidentes que mantenían un lugar en el panorama cultural de la época (agradezco esta última observación a un/a evaluador/a de este trabajo).

${ }^{33}$ Informe del Departamento de Inteligencia 122 del Ejército del 19 de abril de 1979 sobre la Biblioteca Moreno e informe de igual fuente del 29 de agosto de 1980 sobre antecedentes de grupos de cine y teatro en respuesta a requerimiento de la Dirección General de Informaciones de la Provincia (AMPSF).

${ }^{34}$ Con dirección invitada de Roberto Lemes, música de Osvaldo y Hugo Maggi, Carlos Gianni y Eduardo Segal. Los demás aspectos serían cubiertos por los técnicos del teatro Municipal "siempre eficientes y de buena voluntad", según declaraciones de los integrantes del Llanura en Diario El Litoral, 6 de junio de 1980, p. 11. Ricci diría más adelante: “Tomé una serie de elementos del circo tradicional pero como excusa para reflexionar sobre la problemática del actor que evidentemente me persigue como una obsesión... Por eso Zapatones inicia esa cuestión un tanto existencial que se mantiene a través del tiempo" (Ricci, 2004; según el entrevistador, Ricci consideraría a esa obra como "la prehistoria" de la laureada Actores de Provincia, que interpretaría más adelante con Rafael Bruza).

${ }^{35}$ Diario El Litoral, 12 de junio de 1980, p. 13, nota firmada por "R. A.". 
logrado y la que supuso su consolidación en el ámbito santafesino y el inicio de su proyección nacional. Fue realizada sobre el texto de Roberto Arlt, según la versión de Rodolfo Aldasoro. ${ }^{36}$ Se estrenó en 1981 en Santa Fe y al año siguiente participó de la segunda edición de Teatro Abierto, en un contexto de clara oposición a la dictadura militar y junto con piezas notoriamente políticas. ${ }^{37}$

El montaje de El Jorobadito por el Llanura fue claramente rupturista respecto de la gubernamentalidad autoritaria en su conjunto, tanto desde la perspectiva de una crítica a la "clase media hipócrita" (Ricci, 2005: 179) como desde la estética teatral. No presentaba una escenografía, vestuario o técnicas complejas, sino que en su austeridad recordaba los postulados del "teatro pobre" de Grotowski y ponía el acento en el trabajo y en el nivel actoral. Al decir de María Rosa Pfeiffer, la puesta en escena era transgresora y el involucramiento de los cuerpos de los actores muy profundo, al punto que desde la perspectiva de Reynoso Aldao era altamente criticable que anduvieran "tirándose por el suelo" (Pfeiffer, 2017). Era ya una transición hacia otra estética teatral, solidaria con una crítica social que no asumía claramente un discurso político y -que poniendo el énfasis en la corporeidad y las relaciones interpersonales- se alejaba de las perspectivas revolucionarias y colectivistas de finales de 1960 e inicios de 1970.

Hacia 1984 Ricci escribiría una serie de reflexiones criticando el carácter imitativo del teatro del interior respecto de Buenos Aires y planteando las posibilidades de construcción de una poética grotesca que entremezclase humor y drama para hablar "de cosas que tienen que ver con el paisaje en el que nosotros nos movemos", postulando un teatro sin normas restrictivas, es decir, un "teatro salvaje" (Ricci, 1986). Para ese entonces ya se insertaba nuevamente en la Universidad Nacional del Litoral, donde sería por muchos años Director de Cultura.

Barriendo todo el arco temporal de este escrito, su trayectoria muestra algunos elementos distintivos. Una cierta vinculación inicial con agentes políticos de izquierda, nunca muy fuerte ni bien definida. El paso por experiencias teatrales innovadoras con criterios de vanguardia hacia el final de los ‘60, para luego llegar a una inserción plena en la institución arte de la escena

${ }_{36}$ El Jorobadito fue dirigida por Jorge Ricci, contó con la actuación de Rafael Bruzza, Rubén Gattino, Daniel Machado, María Rosa Pfeiffer, Juan Carlos Rodríguez y Humberto Torres. El vestuario y la escenografía fueron créditos del Equipo Llanura, la iluminación de Miguel Novello y la música de Jorge Molina.

${ }^{37}$ De acuerdo con Mauricio Kartun, en 1981 Teatro Abierto había reunido obras "que andaban dando vueltas y que se habían armado sin la necesidad de tener que dar una opinión sobre la dictadura", pero para 1982 “todos querían, de alguna manera, «decir algo» y se ponían enfáticos en su «versión monstruosa del Falcon»". De esa manera se "Abrió un concurso para definir quién escribía la voz más rotunda en un momento en que todos estábamos «calientes como una pipa»" (Kartun, 2017: 143). 
santafesina desde los años '70 en adelante. Un entramado social articulado en torno a experiencias estudiantiles universitarias y una relación ambivalente con poderes públicos fragmentados, algunos de los cuales propiciaban su cesantía o vigilaban sus actividades mientras otros lo contrataban o le brindaban su apoyo. Por fin, en Ricci se aprecia el relevo generacional de la comunidad teatral hacia el final de la última dictadura y una perspectiva ulterior de incorporación a la gestión universitaria en el período constitucional.

Mucho más breve en lo que toca a este recorte temporal fue el trayecto de María Rosa Pfeiffer. Se había radicado en Santa Fe hacia 1976 para estudiar teatro y artes visuales, proveniente de una familia de clase media del pequeño pueblo de Humbolt, distante a 50 kilómetros. Realizó cursos sobre manejo de títeres y su aplicación pedagógica con Domingo Sahda, con quien participó en 1977 del Elenco Estable de Muñecos de la Provincia. También hizo estudios de literatura y plástica en la Universidad Católica de Santa Fe, pero su formación más importante fue como Profesora Superior de Artes Visuales Especializada en Pintura en la Escuela Provincial "Juan Mantovani". Participante de una cultura de bares y encuentros estudiantiles, fue brevemente detenida en averiguación de antecedentes a la salida del cursado en ese establecimiento, por la homonimia de su apellido con la de un conocido militante santafesino. Años después, rememoraría esa noche en una obra literaria (Pfeiffer, s/f).

Pfeiffer se formó en el Teatro del Actor, pero su debut fue con el Llanura en Zapatones. La obra tenía con dos personajes: un viejo clown representado por Ricci y un pibe representado por Pfeiffer. Para María Rosa fue un momento trascendente y destacaría que la recepción por el público "fue fantástica" (Pfeiffer, 2017). Representó no solo su inicio actoral, sino también la participación en un elenco reconocido y con un actor/autor en proceso de consagración. Su participación en El Jorobadito fue más disruptiva y de esa obra destacó en distintas ocasiones su crudeza y la puesta en cuestión de las representaciones de género. En su rememoración, el elemento más urticante era que el actor que representaba a una mujer mayor -Juan Carlos Rodríguez F.- lo hiciera sin afeitarse los bigotes, en tanto que en lo personal destacaba una escena en la cual Rafael Bruza y ella interpretaban una situación onírica de contenido sexual. María Rosa recordaba que en una de las presentaciones se encontraba su madre entre el público y que "...se había clavado las uñas en las rodillas y se las dejó marcadas..." (Pfeiffer, en Schneider y Bucci, 2013: 25).

A la par que se dedicaba al teatro, se mantuvo activa en el área de plástica. Además de ejercer la docencia hizo el diseño de programa y el maquillaje para Zapatones, en 1981 dictó un curso sobre "Escultores santafesinos" en el Museo Municipal de Artes Visuales y pintó un mural en la Iglesia de San Antonio, y en 1983 participaría con dibujos en una muestra de artistas santafesinos. En 1984 asistió al Festival Latinoamericano de Teatro de Córdoba y se sintió impactada por el ambiente cultural y político "mucho más 
combativo", al punto de decidir mudarse a esa ciudad e iniciar un breve acercamiento al peronismo de izquierdas (Pfeiffer, 2017). ${ }^{38}$

Pfeiffer parece presentar un cierto contrapunto respecto de Ricci, no solo en sus roles -fuertemente condicionados por la situación de género y la edadsino también por la diferencia de su periplo ideológico, con una socialización política posterior y una búsqueda de espacios más combativos en momentos en los que el segundo se insertaba en la institucionalidad democrática. Sin embargo, ambos compartieron un espacio de formación superior al de sus momentos etarios o sus inscripciones políticas, dado por su pertenencia a cierta clase social y su relación con los ámbitos educativos de las humanidades y las artes. Como muchas de las personas que descollaron en la actividad teatral santafesina de la década de 1970, Ricci y Pfeiffer ya no se inscribían como sus padres en una clase media de pequeños propietarios o empleados de cuello blanco, sino en una fracción correspondiente a los servicios sociales y culturales y en especial a la docencia en literatura y artes plásticas. Probablemente en esos espacios y en las relaciones interpersonales se encuentren las claves de una "educación sentimental" - distinta de la educación formal que a veces compartían- que permita explicar cómo en esos momentos una mujer o un hombre de un entorno social preciso se convierten en actrices o actores, directores o directoras, autoras o autores, capaces de trascender sus localidades.

\section{Conclusiones}

Una selección diferente de variables podría dar por resultado una periodización diferente del teatro independiente santafesino que la que se postuló al inicio de este escrito. Sin embargo, del repaso de los desarrollos presentados podrían postularse algunos aspectos que caracterizarían al movimiento de conjunto:

Primero, la conformación de una comunidad teatral en el seno de articulaciones socio-políticas complejas, entre las que destacan una inscripción en clases medias variadas y una relación ambivalente con las reparticiones estatales, incluso en los períodos dictatoriales. En esa comunidad teatral fueron adquiriendo cada vez más presencia personas con títulos docentes en disciplinas artístico-culturales, en un proceso acorde al paso del teatro independiente al neoindependiente en el sentido de una mayor profesionalización (véase nota 7).

Luego, el paso del teatro independiente a las primeras experiencias neoindependientes, lo que supondría una triple dimensión: a) el tránsito de una autonomía relativa de los agrupamientos teatrales vocacionales a una inscripción institucional relativa, reconfigurada con la transición a la democracia y caracterizada por el apoyo material a los elencos; b) el paso de la

\footnotetext{
38 Sobre estos festivales y su papel en el proceso de democratización véase Heredia (2013).
} 
elección entre de diversos modelos de hacer teatro a una situación en la cual los elencos se despegaban de recetas para experimentar constantemente; y c) el movimiento de la posibilidad de unir en la vanguardia arte y vida en algunas experiencias, a otro momento en el cual la recuperación de los elementos estéticos se realizaba con criterios de posvanguardia respetando la forma de la institución arte.

En tercer lugar, tendríamos la posibilidad de identificar subjetividades disidentes, que no se presentaron con discursos de clara confrontación pero que encontraron modos de poner en cuestión en el plano de los discursos teatrales tanto a los autoritarismos dictatoriales como a la más difusa gubernamentalidad autoritaria santafesina.

Todos esos tránsitos suponen a su vez la posibilidad de identificar las trayectorias individuales de personas determinadas, que se construyeron como sujetos en procesos de educación sentimental más que formal, a similitud de personajes literarios como Frédéric Moreau (Flaubert, 2015). Sin dudas los espacios institucionales como la Escuela Universitaria del Profesorado o la Escuela Provincial de Artes Visuales eran lugares de interacción y formación de nuevas camadas de personas dedicadas al teatro, pero también es correcto que la apertura a nuevas experiencias y posicionamientos sociales no puede atarse al efecto educativo formalizado, sino que sería expectable encontrar en sus vínculos personales, en los mismos ámbitos teatrales o culturales compartidos y en la interacción social en sentido amplio los canales de una constitución de subjetividades disidentes. Esos casos serían los de integrantes de una "clase media ilustrada" que según Jorge Ricci era el motor del teatro independiente y luego neoindependiente (Ricci, 2005b: 165). Sería interesante entonces profundizar la indagación en historias de vida para apreciar cómo esas personas pudieron producir un sujeto colectivo, movilizando emociones, configurando sensibilidades respecto de lo social y de su propia labor teatral y resistiendo -a su manera- el régimen emocional que les ofrecía un contexto social limitado tanto en períodos constitucionales como dictatoriales.

\section{Bibliografía y entrevistas citadas}

Alonso, Luciano (2011). Luchas en plazas vacías de sueños. Movimiento de derechos humanos, orden local y acción antisistémica en Santa Fe, Rosario: Prohistoria.

Alonso, Luciano (2015). "Redes y dimensiones espaciales en la movilización por los derechos humanos en Argentina”. Avances del Cesor vol. XII, núm. 12.

Alonso, Luciano (2017). “Teatro en transición. Dramaturgia, política y relaciones sociales en Santa Fe (Argentina), entre la última dictadura y la 
transición democrática". RBBA - Revista Binacional Brasil Argentina vol. 6, núm. 2.

Baeza, Federico (2017) Proximidad y distancia, Arte y vida cotidiana en la escena argentina de los 2000, Buenos Aires: Biblos.

Bourdieu, Pierre (1993). Entrevista "La lógica de los campos". Zona Erógena № 16.

Bürger, Peter (2010). Teoría de la vanguardia, Buenos Aires: Las Cuarenta.

Campana, Jorge (1999). Crónica sobre la política cultural de los gobiernos santafesinos (1920-1999), Rosario: Ediciones Culturales Santafesinas.

Flaubert, Gustave (2015) La educación sentimental, Madrid: Peguin.

Foucault, Michel (2006). Seguridad, territorio, población, Curso en el Collège de France (1977-1978), Buenos Aires: Fondo de Cultura Económica.

Gómez, Josefina (2007). La cultura santafesina durante los años de plomo, Santa Fe, Producciones Especiales Diario El Litoral.

Grotowski, Jerzy y otros (1992). Hacia un teatro pobre, México: Siglo XXI.

Heredia, Verónica (2013). “Los Festivales Latinoamericanos de Teatro en Córdoba: escenarios de la democracia", ponencia ante las XIV Jornadas Interescuelas / Departamentos de Historia, Universidad Nacional de Cuyo, Mendoza.

Iriondo, Liliana (1995). "La puesta en escena en el interior", en Pellettieri, Osvaldo y Rovner, Eduardo, coords. La puesta en escena en Latinoamérica: teoría y práctica teatral, Buenos Aires: Galerna

Kartun, Mauricio (2017). “De Teatro Abierto a Terrenal. «Todo teatro está basado en la hipótesis del enfrentamiento y la violencia»", entrevista por Verónica Perera y Maximiliano de La Puente. Clepsidra. Revista Interdisciplinaria de Estudios sobre Memoria vol. 4, núm. 7.

Kershaw, Ian (2004). La dictadura nazi. Problemas y perspectivas de interpretación, Buenos Aires: Siglo XXI.

Logiódice, María Julia (2015). “Políticas teatrales en Santa Fe (1940-1989). Articulaciones entre teatro independiente rosarino y Estado provincial". Revista SAAP vol. 9, núm. 1.

Marcuse, Herbert (1978) "Acerca del carácter afirmativo de la cultura", en Cultura y sociedad, Buenos Aires: Sur.

Müller, Walter (1999) "La estructura de clases y el sistema de partidos", en Zona Abierta núm. 86/87. 
Pellettieri, Osvaldo (1994). "Brecht y el teatro porteño (1950-1990)", en Pellettieri, Osvaldo, ed. De Bertold Brecht a Ricardo Monti. Teatro en lengua alemana y teatro argentino (1900-1994), Buenos Aires: Galerna.

Pellettieri, Osvaldo, dir. (2005). Historia del teatro argentino en las provincias, vol. I, Buenos Aires: Galerna.

Pfeiffer, María Rosa (2017). Entrevista personal por Luciano Alonso, Santa Fe, 11 de abril.

Pfeiffer, María Rosa (sf). "Mi papá y Perón”, cuento presentado al Concurso de Cuento Corto Latinoamericano, en línea en http://www.servicioskoinonia.org/cuentoscortos/articulo.php?num=046, consulta mayo de 2018.

Pisarello, María Virginia (2013). "La "ilusión democrática" a través del diario El Litoral, 1983-1987", en Falchini, Adriana y Alonso, Luciano (eds.). Los archivos de la memoria. Testimonios, historia y periodismo, Santa Fe: Universidad Nacional del Litoral.

Ramírez, Paula (2016). Arte y politica en la ciudad de Santa Fe. Relaciones entre los artistas emergentes culturales santafesinos y el proceso general de radicalización política en los años 60, tesina de Licenciatura en Historia, Santa Fe: Universidad Nacional del Litoral, mimeo.

Reynoso Aldao, Jorge (2012) Entrevista por Darío Macor y Marcelino Maina, 16 de marzo, Santa Fe, Programa de Historia y Memoria de la Universidad Nacional del Litoral - Archivo de Historia Oral.

Ricci, Jorge (1986). Hacia un teatro salvaje, Santa Fe: Universidad Nacional del Litoral.

Ricci, Jorge (2004). Entrevista "Hacer Teatro es un milagro". Cuadernos del Picadero núm. 2.

Ricci, Jorge (2005a). “Santa Fe, 1900-1999”, en Pellettieri, Osvaldo (2005).

Ricci, Jorge (2005b). “Momentos del Teatro Argentino (Ensayo Breve)”. Texturas núm. 3.

Ricci, Jorge, comp. (2012a). Inventario del teatro independiente de Santa Fe, vol. I, Santa Fe: Universidad Nacional del Litoral.

Ricci, Jorge (2012b). Entrevista "Jorge Ricci: 'nada es totalmente nuevo en el teatro'", en línea el 28 de noviembre en http://www.lagaceta.com.ar/nota/522572/espectaculos/jorge-ricci-nadatotalmente-nuevo-teatro.html.

Ricci, Jorge (2014a). Entrevista "Jorge Ricci, 40 años al frente del santafesino Grupo Llanura", en línea el 9 de junio en 
http://www.telam.com.ar/notas/201406/66490-jorge-ricci-40-anos-al-frente-delsantafesino-grupo-llanura.html.

Ricci, Jorge (2014b). Entrevista personal por Laura Schenquer y Luciano Alonso, Santa Fe, 30 de abril.

Schenquer, Laura (2016). “Políticas culturales de la última dictadura de Argentina: construir consensos y cooptar a la población. El Teatro para la Salud de Santa Fe", en Afuera. Estudios de crítica cultural núm. 16.

Schneider, Roberto (2011). Entrevista "Roberto Schneider y el teatro", en línea el 6 de febrero de 2011 en http://agenciafe.com/wblogs/index.php?acc=ficha\&idart=89801).

Schneider, Roberto y Bucci, Verónica, comps. (2013). Inventario del teatro independiente de Santa Fe, vol. II, Santa Fe: Universidad Nacional del Litoral.

Wright, Erik Olin (1989) “¿Qué tiene de media la clase media?”, en Roemer, John E., comp. El marxismo: una perspectiva analítica, Fondo de Cultura Económica, México, 1989

Zayas de Lima, Perla (1990). Diccionario de directores y escenógrafos del teatro argentino, Buenos Aires: Galerna.

Santo Tomé, junio de 2020. 